\title{
A COMMON DISEASE PRESENTING IN UNCOMMON WAY AT UNCOMMON LOCATIONS - GIANT ACROCHORDONS (2 CASE REPORTS)
}

Sudha Madhuri Basaboina1, Gitu Duara²

HOW TO CITE THIS ARTICLE:

Sudha Madhuri Basaboina, Gitu Duara. "A Common Disease Presenting in Uncommon way at Uncommon Locations - Giant Acrochordons (2 case reports)". Journal of Evolution of Medical and Dental Sciences 2014; Vol. 3, Issue 08, February 24; Page: 1946-1948, DOI: 10.14260/jemds/2014/2085

ABSTRACT: Acrochordons are soft, skin colored pendunculated lesions primarily seen in skin creases such as neck, armpit, eyelids, trunk \& groins. Etiology of skin tags is unknown but they tend to occur in obese people and frequent irritation seems to be an important causative factor. A pedunculated small acrochordons can be removed with curved or serrated blade scissors; larger skin tags may require excision. For small acrochordons, application of aluminum chloride prior to removal will decrease the amount of minor bleeding.

KEYWORDS: Acrochordons, uncommon location.

Acrochordons (Skin tag/Fibroepithelial polyp) are soft, skin colored pendunculated lesions primarily seen in skin creases such as neck, armpit, eyelids, trunk \& groins ${ }^{1}$. Usually they are $1 \mathrm{~mm}-$ $5 \mathrm{~mm}$ in size and so remain unnoticed.

Giant acrochordons at unusual sites are rarely reported in literature.

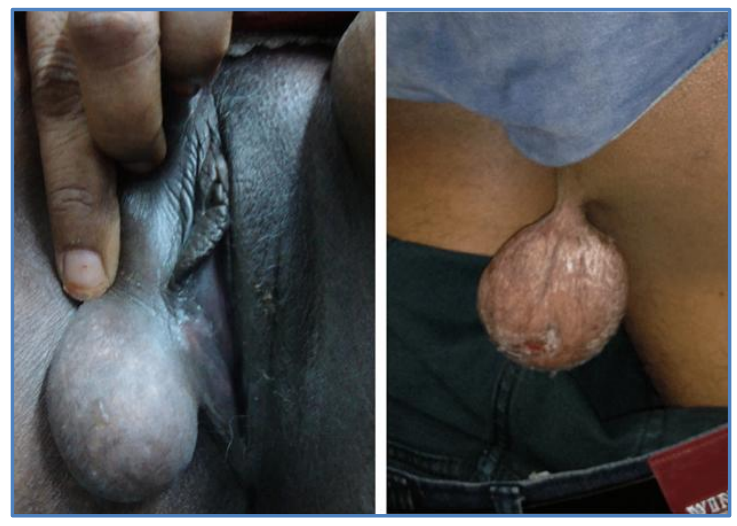

Case report 1: A 36yr old multi parous woman presented with $10 x 7 \mathrm{cms}$ large fleshy soft mass attached to the skin with soft thin stalk over right labium majus since 5yrs. This is one of the few largest skin tags reported in the vulva.

Case report 2: A 28yr old male presented with $12 x 12 \mathrm{~cm}$ spherical, skin colored, pedunculated bag like mass on the back of the right thigh since 10 yrs with H/o difficulty in sitting posture. Surface ulcerated due to constant rubbing.

Given the soft consistency, pendunculated nature with free mobility a diagnosis of skin tag was made. Friction ${ }^{2}$ against tight fitting undergarment may be the initiating factor in this case. To the best of our knowledge, this is the first case report of giant acrochordons on the posterior thigh.

Systemic examination, GTT, Lipid profile was normal in both cases. 
Total excision done under local anesthesia and diagnosis was confirmed by histopathological examination.

\section{Histopathology:}

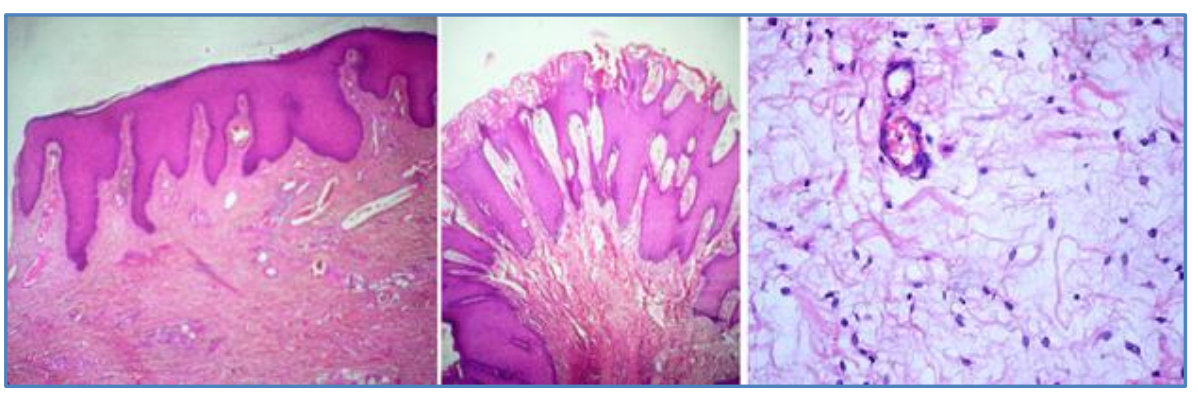

Acanthosis Papillomatosis Fibroblast \& Dilated Blood Vessels Fibrovascular tissue

DISCUSSION: Etiology of skin tags is unknown but they tend to occur in obese people and frequent irritation seems to be an important causative factor. Epidermal growth factor \& tissue growth factor are implicated in their development. Usually asymptomatic, may be painful secondary to local trauma or torsion and infarction in rare cases. Generally diagnosed by clinical features however histology is needed in unusual cases.

DM, Insulin resistance, Obesity, Acromegaly, Colonic polyps, impaired carbohydrate and lipid metabolism ${ }^{3}$, pregnancy and Birt Hogg-Dube syndromes ${ }^{4}$ are possible associations.

Differential diagnosis: benign neoplasms like lipoma, fibroma, seborrheic keratosis, warts, fibrofolliculomas and malignant lesions like Angiomyxoma, Dermatofibrosarcoma protuberans.

CONCLUSION: Skin tags are common in general population but it very rare to find giant skin tags at unusual sites like in our cases. A giant acrochordon though benign may generate anxiety in both clinician and patient in view of possible differential diagnosis. A multidisciplinary input comprising of dermatologist, surgeon \& pathologist \& follow up should be considered by clinicians.

\section{REFERENCES:}

1. Susana Canalizo - Almada, Patricia Mercadillo Perez, Giant skin tags - Reports of two cases. Dermatology Online Journal, 2007.

2. Allegue F, Fachal C, Perez-Perez L, Friction induced skin tags. Dermatologica 1987; 174-180, Volume - 3 .

3. Fauzia Naureen Bhutta, Rubina Ali, Shazia Shahin, A Giant Skin tag on Labium Majus, APMC Volume 7 No 1 Jan-June 2013.

4. Ahmet Ali Sancaktutar, Scrotal skin and Acrochordon. Journal of Clinical and Analytical Medicine. 


\section{CASE REPORT}

\section{AUTHORS:}

1. Sudha Madhuri Basaboina

2. Gitu Duara

\section{PARTICULARS OF CONTRIBUTORS:}

1. Post Graduate, Department of Dermatology, KIMS \& RF, Amalapuram.

2. Assistant Professor, Department of Dermatology, KIMS \& RF, Amalapuram.

\section{NAME ADDRESS EMAIL ID OF THE} CORRESPONDING AUTHOR:

Dr. Sudha Madhuri Basaboina,

House No. 7-18/31,

Raghavendra Nagar,

Nacharam, Hyderabad - 500076.

E-mail: drsudhamadhuri1@gmail.com

Date of Submission: 15/02/2014. Date of Peer Review: 17/02/2014.

Date of Acceptance: 19/02/2014.

Date of Publishing: 21/02/2014. 